\title{
11
}

\section{China's growth to 2030: demographic change and the labour supply constraint}

\author{
Jane Golley and Rod Tyers
}

The world's most populous country has entered a period of rapid ageing, with the proportion of the population over the age of 60 projected to double in the next 25 years (United Nations 2005). This represents a significant turning point in China's economic development and one that places China in the unique position of being a transitional developing economy facing what is primarily an industrial-country phenomenon. As is so often the case for China, the appropriate policy responses are therefore likely to be unique as well. In particular, while many industrial countries are seeking ways to deal with ageing, such as pro-fertility policies, immigration and later retirement ages, developing countries are trying to ensure that their growing working-age populations can be absorbed into the workforce, through labour-market reforms and better education and training (International Monetary Fund 2004). As China's economic development and transition progress in the context of population ageing, Chinese policymakers will need to look both ways.

The demographic transition to slower population growth and the associated ageing of China's population have been profoundly affected by the one-child policy. Yet fertility rates would have declined anyway, affected as they have been in China's Asian neighbours by urbanisation, female education, higher labour-force participation rates, the improved life expectancy of new-born children and the high parental cost of preparing for and supporting children through increasingly competitive education systems. With a transition to a declining population in prospect, and with competing developing regions such as South Asia set to enjoy 
continued demographic dividends, there is now extensive discussion of whether the State should encourage higher fertility by relaxing its family planning policies. ${ }^{1}$

Indeed, unless there is a substantial change in population policy, the achievement of China's ambitious GDP growth objectives ${ }^{2}$-and, therefore, the retention of China's large share of global investment-will require further improvements in its investment environment, in its organisation of production and hence factor productivity and/or in its labour-force participation. Aged participation is low in China by Asian standards, but there are numerous reasons why we might expect an upward trend approaching the rates observed in neighbouring countries such as Japan. In this chapter, the linkages between demographic change, labourforce participation and economic growth are explored using a new global demographic sub-model, which is integrated with an adaptation of the GTAPdynamic global economic model in which regional households are disaggregated by age and gender. In particular, the model is used to explore the growth implications of alternative fertility policies and increased aged participation.

The chapter proceeds as follows. The next section discusses recent trends in fertility, ageing and labour-force participation rates in China, along with related policy options. This is followed by a general description of the demographic submodel, along with its integration within the GTAP-dynamic. Next, a baseline scenario is constructed for the global economy through to 2030, after which the results for alternative assumptions about fertility rates and aged labour-force participation are presented. Policy suggestions are offered in the conclusions.

\section{Fertility, ageing and labour-force participation in China}

While debates over the extent of China's fertility decline continue, it is widely accepted that by the turn of this century fertility rates had fallen to well below the replacement level of 2.1 births per woman. According to the National Bureau of Statistics (2002), the total fertility rate in 2000 was 1.22 children per woman, although even the Chinese government recognised that the figure was more like 1.8 because of under-reporting of births in surveys and censuses (Sharping 2003). Zhang and Zhao (2006) provide an extensive survey of the literature on fertility decline in China during the past two decades and conclude that the total fertility rate probably fell to about 1.6 by 2000 . In a survey of rural women, Chu (2001) found many of them wanting fewer children, primarily because of new financial constraints associated with rapid increases in school fees and the cost of living. Retherford et al. (2005) concur that rapid fertility decline is highly plausible in light of China's rapid economic development and the socioeconomic forces unleashed 
by market reforms, combined with the one-child policy. While the causes are not the same, China's low and declining fertility rates place it alongside many industrial countries, including most Western European countries and Japan.

A declining fertility rate has been a major contributing factor to China's demographic transition. ${ }^{3}$ The United Nations (2005) projects that the percentage of the population over 60 years of age will rise from 10 per cent in 2000 to 20 per cent by 2025 and 31 per cent by $2050,{ }^{4}$ while the percentage of the working-age population (aged 15-59 years) will fall by more than 10 percentage points during the same period. It is thereby suggested that some time between 2015 and 2020, the growth of the working-age population will become negative, in turn suggesting that GDP growth will suffer as a consequence.

To illustrate the striking slowdown in China's total population and labour force that is implied by the baseline projection in our model (discussed in detail below), both are contrasted with those of India (Figure 11.1). China's population is seen to begin declining during the next decade while its labour force declines earlier than that. Even though India is also ageing, its most populous age groups are very young

\section{Figure 11.1 China's and India's projected populations and labour forces,} 1995-2035
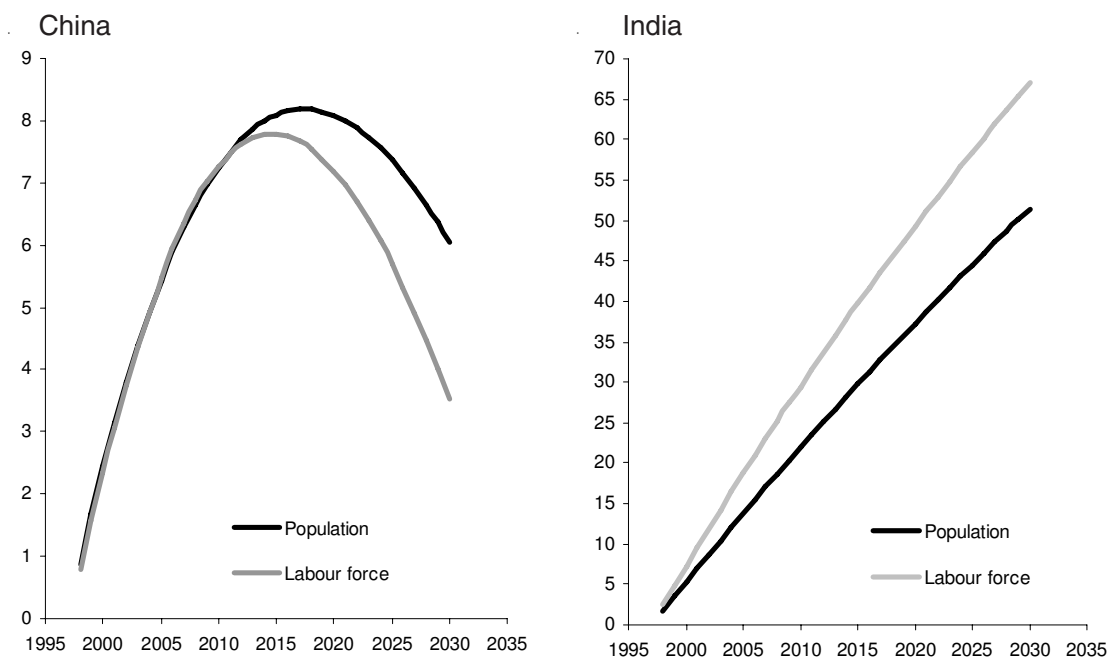

Note: a These are cumulative percentage departures from the base year, 1997, drawn from the baseline simulation in which China's fertility is projected to decline faster than India's and in which India begins with a much younger population.

Source: Baseline model simulation. 
and, as these groups age, they raise the labour-force participation rate and the crude birth rate. Thus, in a period during which China's labour force shows little net growth, India's labour force rises by half. The same pattern is observed in other populous developing countries in South Asia and Africa. Compared with the rest of the developing world, then, the slow down in China's population must be expected to constrain its labour supply and hence to retard its overall economic expansion.

There are numerous policies that could potentially offset the negative consequences that China's pending demographic change will have for economic growth, including measures to increase fertility and labour-force participation rates. ${ }^{5}$

Fertility rates are key determinants of the rate of population growth and, in China, they have long been policy targets. Controlling for numerous other factors that affect population growth (including urbanisation, female education, increases in labour-force participation and improved life expectancy), Sharping (2003) estimates that, in the absence of the State's birth-control policies, China's population would have been 1.6 billion instead of the 1.27 billion reported at the end of the twentieth century. The question that remains is whether pro-fertility policies will impact significantly on fertility rates in the future. According to Demeny (2003:14), in the past the family planning programs that were most effective in reducing fertility rates in developing countries tended to work via 'heavy-handed methods of persuasion, and, in the especially important case of China, by coercion backed by legal sanctions'. The Chinese government is unlikely to utilise such methods to raise fertility rates in the future, and would instead need to resort to fiscal measures (such as tax breaks and family allowances) and policies to make motherhood and the women's labour force more compatible (through day-care services and more flexible working hours). Yet even if such policies were implemented-in itself a long shot-the impact on fertility rates is uncertain at best. ${ }^{6}$ Moreover, there would clearly be a long lag before such policies, even if effective, would lead to an increase in the working-age proportion of the population and hence lower dependency rates.

An alternative policy approach would be to direct attention towards labour-force participation rates. Recent evidence suggests that labour-force participation by China's aged population is relatively low compared with other Asian economies. According to Jackson and Howe (2004), in 2000 the labour-force participation rates of men aged between 60 and 64 and over 65 were 60 per cent and 28 per cent respectively. For the same age groups, these percentages were 83 and 55 in the Philippines, 72 and 33 in Japan and 64 and 44 in Vietnam. Only Hong Kong and Singapore had lower participation rates in both age groups. Chan and Tyers (2006) provide a comparison of age and gender-specific labour-force participation rates in China and Japan in 1997 (the baseline year in the simulations conducted 
below), they find participation rates of 91 per cent and 43 per cent for 40-59-yearold Chinese males and females respectively, compared with 97 per cent and 67 per cent in Japan. Among those aged 60 and over, 24 per cent of Chinese men and just 4 per cent of Chinese women participated in the labour market, compared with 46 per cent of Japanese men and 23 per cent of Japanese women.

Labour-force participation rates were not only low at the turn of the century, but declining (Chan and Tyers 2006; Giles et al. 2006). Using data from the China Urban Labour Survey of five large cities conducted at the end of 2001, Giles et al. (2006) analysed the impact of economic restructuring on urban workers between 1996 and 2001, a period of widespread, large employment shocks in the labour market. During this period, unemployment reached double figures in all five cities, while labour-force participation declined by nine percentage points. The decline was most pronounced among workers approaching mandatory retirement: a 19 percentage point drop in participation rates of men aged 55-60 (down to 57 per cent in 2001) and an 11 percentage point drop for women aged 50-55 (down to just 34 per cent). These substantial declines are attributed to the replacement of implicit lifetime employment with massive lay-offs, widespread unemployment and forced early retirements.

Yet there are numerous reasons why China's labour-force participation rates could be higher in the future. Perhaps the most obvious of these would be an increase in the retirement age. In an influential World Bank (1997a) report on China's social security system, it was noted that current retirement ages of 60 for men and 55 for women were set at a time when life expectancy was only 50 years, compared with 71 years now. The report called for a gradual increase in the retirement age to 65 years, and even higher as longevity continues to increase.

It is obvious that the nature of any country's pension system will impact on retirement decisions and therefore on aged participation rates, although it is far from clear what the impact of continuing reforms on China's pension system will be. A multi-pillar system combining a pay-as-you-go component, a mandatory individual account and a voluntary supplementary scheme, first introduced in 1997, is being implemented in traditional Chinese fashion on an experimental and gradual basis. ${ }^{7}$ Among other objectives, the introduction of individual accounts is intended to 'instil a spirit of self-help among workers who would look after their own retirement costs rather than depend on contributions from their children' (World Bank 1997a), thereby providing incentives to save more and retire later.

In 2000, 100 million workers were covered by the pension system in China, financing the pensions of 32 million retirees. This means that less than 10 per cent of the total population was covered (James 2001). The majority of this 10 per 
cent were employed by SOEs and urban collectives, with extremely low coverage in foreign-funded and private enterprises, and in rural areas. This low coverage implies that, in the foreseeable future, the majority of old people will not receive a pension and will have to rely on personal savings and a diminishing family system (James 2001). As the share of people employed in non-state sectors continues to rise, and as long as a majority in non-state enterprises continue to opt out of the pension system, it is likely that China's elderly will necessarily need to work longer in order to finance their retirement needs.

Of course, pension-related incentives for older generations to continue working are of little help if labour markets are inflexible or unable to absorb them. Despite significant improvements in the functioning of Chinese labour markets in the past three decades, there are still serious barriers preventing their efficient operation. Local protectionism and institutional barriers connected to the hukou system prevent potential gains from labour reallocation between rural and urban areas from being realised, while urban labour-market reforms are restricted by the fiscal burden of paying unemployment benefits and pensions (Fleisher and Yang 2003). Until the late 1990s at least, the lack of portability of the pension system impeded labour mobility, in turn reducing participation rates (World Bank 1997a). As solutions to these issues emerge, labour-force participation rates should rise, although there is clearly uncertainty as to when and how such solutions will materialise.

Bearing in mind the obvious uncertainties associated with identifying the extent to which various policies will impact on aged participation and fertility rates, in what follows we propose some plausible alternative scenarios and then demonstrate that the implications for GDP and real per capita income growth rates vary significantly depending on whether fertility or participation is targeted.

\section{Modelling the economic implications of demographic change}

The approach adopted follows Tyers (2005) and Tyers and Shi (forthcoming), in that it applies a complete demographic sub-model that is integrated within a dynamic numerical model of the global economy. ${ }^{8}$ The economic model is a development of GTAP-dynamic, the standard version of which has single households in each region and therefore no demographic structure. ${ }^{9}$ The version used has regional households with endogenous savings rates that are disaggregated by age group, gender and skill level.

\section{Demography}

The demographic sub-model tracks populations in four age groups and two genders: a total of eight population groups in each of 14 regions. ${ }^{10}$ The four age groups are 
the dependent young, adults of fertile and working age, older working adults and the mostly retired over-60s. The resulting age-gender structure is displayed in Appendix Figure 11.1. The population is further divided between households that provide production labour and those providing professional labour. ${ }^{11}$ Each age-gender-skill group is a homogeneous subpopulation with group-specific birth and death rates and rates of immigration and emigration..$^{12}$ If the group spans $T$ years, the survival rate to the next age group is the fraction $1 / T$ of its population, after group-specific deaths have been removed and its population has been adjusted for net migration.

The final age group (60+) has duration equal to measured life expectancy at 60 . It varies across genders and regions. The key demographic parameters, then, are birth rates, sex ratios at birth, age and gender-specific death, immigration and emigration rates and life expectancies at $60 .{ }^{13}$ The migration rates are based on recent migration records and are held constant through time. ${ }^{14}$ The birth rates, life expectancy at 60 and the age-specific mortality rates all trend through time asymptotically. For each age group, gender group and region, a target rate is identified. ${ }^{15}$ The parameters then approach these target rates with initial growth rates determined by historical observation.

A further key parameter is the rate at which each region's education and social development structure transforms production-worker families into professionalworker families. Each year a particular proportion of the population in each production-worker age-gender group is transferred to professional (skilled) status. These proportions depend on the region's levels of development, the associated capacities of their education systems and the relative sizes of the production and professional labour groups. The skill transformation rates are based on changes during the decade prior to the base year, 1997, in the composition of aggregate regional labour forces as between production and professional workers. These are also held constant through time. ${ }^{16}$

Labour force projections. To evaluate the number of 'full-time equivalent' workers, we first construct labour-force participation rates by gender and age group for each region from International Labour Organization (ILO) statistics on the 'economically active population'. We then investigate the proportion of workers who are part-time and the hours they work relative to each regional standard for full-time work. The result is the number of full-time equivalents per worker. ${ }^{17}$

For each age group, gender group and region, a target country is identified whose participation rate is approached asymptotically. As with birth and death rates, the rate of this approach is determined by the initial rate of change. Target rates are chosen from countries considered to be advanced in terms of trends in participation rates. Where female participation rates are rising, therefore, Norway 
provides a commonly chosen target because its female labour-force participation rates are higher than for other countries. ${ }^{18}$

The aged dependency ratio. We define and calculate four dependency ratios: a youth dependency ratio is the number of children per full-time equivalent worker; an aged dependency ratio is the number of people over 60 per full-time equivalent worker; a non-working-aged dependency ratio is the number of non-working people over 60 per full-time equivalent worker; and a more general dependency ratio is defined that takes as its numerator the total non-working population, including children. ${ }^{19}$

The baseline population projection for China. The two key population parameters of interest—birth rates and labour-force participation rates-are listed in Tables 11.1 and 11.2, along with their assumed trends through to 2030. In these tables, the parameters are contrasted with those for Japan, towards whose development path China might be expected to trend in the coming decades. Most notable is the declining trend in Chinese fertility, extending the fall during the decade prior to the base year (1997) in an asymptotic approach towards the rates observed in Japan. The trends in participation rates assume that no significant policy changes take place, with slight declines in some of the age groups capturing the possibility that the downward trend observed through the 1990s could continue to some extent in the next 25 years as well. These figures are intended more for comparative purposes than to reflect accurately the expected changes in participation rates in the future.

Birth rates combine with age and gender-specific death rates and life expectancies to determine the baseline population structure, which indicates that the percentage of China's population over the age of 60 will increase from 9.7 per cent in 1997 to 21.5 per cent by 2030 (which is consistent with the UN's [2005] projections) (Table 11.3). The corresponding labour-force projection is summarised in Table 11.4. ${ }^{20}$ Compared with the rest of the developing world, the slow down in China's population will constrain its labour supply and hence retard its economic growth. To assess the impact that this slow down will have, we have embedded the demographic behaviour introduced above in a global economic model.

\section{The global economic model}

GTAP-dynamic is a multi-region, multi-product dynamic simulation model of the world economy. It is a microeconomic model, in that assets and money are not represented and prices are set relative to a global numeraire. In the version used, the world is subdivided into 14 regions, one of which is China. Industries are aggregated into just three sectors: food (including processed foods), industry (mining and manufacturing) and services. To reflect composition differences between 


\section{Table 11.1 Baseline birth rates in China and Japan, 1997-2030}

\begin{tabular}{lcccc}
\hline & \multicolumn{2}{c}{ China } & \multicolumn{2}{c}{ Japan } \\
$\begin{array}{l}\text { Sex ratio at birth, } \\
\text { males:females }\end{array}$ & \multicolumn{2}{c}{$1: 10$} & Birth rate $^{\mathrm{b}}$ & Fertility rate $^{\mathrm{c}}$ \\
& Birth rate $^{\mathrm{b}}$ & Fertility rate $^{\mathrm{c}}$ & 59 & 1.48 \\
Base year, 1997 & 76 & 1.90 & 58 & 1.45 \\
2010 & 62 & 1.55 & 57 & 1.43 \\
2020 & 59 & 1.48 & 57 & 1.43 \\
2030 & 58 & 1.45 & & \\
\hline
\end{tabular}

Notes: ${ }^{a}$ Birth rates are based on UN estimates and projections as represented by the United States Bureau of the Census. The latter representation has annual changes in rates while the UN model has them stepped every five years. Initial birth rates are obtained from the UN model by dividing the number of births per annum by the number of women aged 15-39. These rates change through time according to annualised projections by the US Bureau of the Census. ${ }^{b}$ Birth rates are here defined as the number of births per annum per thousand women of fertile age. They are modified to allow for the modelling simplification that the fertile age group spans 15-39. ' Fertility rates are the average number of children borne by a woman throughout her life.

Source: Aggregated from United Nations, 2003. World Population Prospects: the 2002 revision, UN Population Division, February. Available online at <www.un.org/esa/population/publications/ wpp2002>; US Department of Commerce-US Bureau of the Census, 'International data base', as compiled by Chan, M.M. and Tyers, R., 2006. Global demographic change and labour force growth: projections to 2020, Centre for Economic Policy Research Discussion Paper, Research School of Social Sciences, The Australian National University, December.

\section{Table 11.2 Baseline age and gender-specific labour-force participation rates in China and Japan ${ }^{\text {a }}$ (per cent)}

\begin{tabular}{lcccc}
\hline & \multicolumn{2}{c}{ China } & \multicolumn{2}{c}{ Japan } \\
& Males & Females & Males & Females \\
15-39 Initial (1997) & 79 & 60 & 77 & 55 \\
2030 & 77 & 61 & 76 & 58 \\
$40-59$ Initial (1997) & 91 & 43 & 97 & 67 \\
2030 & 93 & 44 & 97 & 69 \\
$60+$ Initial (1997) & 24 & 4 & 46 & 23 \\
2030 & 17 & 3 & 56 & 49 \\
\hline
\end{tabular}

Notes: ${ }^{\text {a }}$ Projections of these parameters to 2030 assume convergence on target rates observed in comparatively 'advanced' countries, as explained in the text. Only the end-point values are shown here, but the model uses values that change with time along the path to convergence.

Source: Values to 1997 are from Chan, M.M. and Tyers, R., 2006. Global demographic change and labour force growth: projections to 2020, Centre for Economic Policy Research Discussion Paper, Research School of Social Sciences, The Australian National University, December. 
Table 11.3 Baseline population structure in China, 1997-2030

\begin{tabular}{lccc}
\hline & Population (millions) & Female (per cent) & $60+$ (per cent) \\
Initial (1997) & 1,252 & 48.5 & 9.7 \\
2010 & 1,311 & 48.7 & 14.8 \\
2020 & 1,321 & 48.8 & 18.4 \\
2030 & 1,296 & 49.0 & 21.5 \\
\hline
\end{tabular}

Source: Projection using the baseline simulation of the model described in the text.

Table 11.4 Baseline labour-force structure in China, 1997-2030a

\begin{tabular}{lccc}
\hline & Labour force (millions) & Female (per cent) & $40+$ (per cent) \\
Initial (1997) & 585 & 37.6 & 33.8 \\
2010 & 628 & 37.1 & 41.1 \\
2020 & 627 & 36.7 & 44.4 \\
2030 & 606 & 36.5 & 46.6 \\
\hline
\end{tabular}

Note: a Measured in full-time equivalent workers.

Source: Projection using the baseline simulation of the model described in the text.

regions, these products are differentiated by region of origin, meaning that the food produced in one region is not the same as that produced in others. Consumers substitute imperfectly between foods from different regions.

As in other dynamic models of the global economy, in GTAP-dynamic the endogenous component of simulated economic growth is physical capital accumulation. Technical change is introduced in the form of exogenous trends and skill (or human capital) acquisition is driven by the constant transformation rates introduced in the previous section. A consequence of this is that the model exhibits the property of all dynamic models of the Solow-Swan type that incorporate diminishing returns to factor use, namely that an increase in the growth rate of the population raises the growth rate of real GDP but reduces the level of real per capita income. What distinguishes the model from this simpler progenitor are its recursive multi-regional dynamics. Investors have adaptive expectations about the real net rates of return on installed capital in each region. These drive the distribution of investment across regions. In each, the level of investment is determined by a comparison of net rates of return with borrowing rates yielded by a global trust to which each region's saving contributes.

To capture the full effects of demographic change, including those of ageing, the standard model has been modified to include multiple age, gender and skill groups in line with the structure of the demographic sub-model. In the complete model, 
these 16 groups differ in their consumption preferences, saving rates and their labour supply behaviour. Unlike the standard GTAP models, in which regional incomes are split between private consumption, government consumption and total savings via an upper-level Cobb-Douglas utility function that implies fixed regional saving rates, this adaptation first divides regional incomes between government consumption and total private disposable income. The implicit assumption is that governments balance their budgets while private groups save or borrow.

In splitting each region's private disposable income between the eight age-gender groups, the approach is to construct a weighted subdivision that draws on empirical studies of the distribution of disposable income between age-gender groups for 'typical' advanced and developing countries..$^{21}$ Individuals in each age-gender group then split their disposable incomes between consumption and saving. For this, a reduced form of approach is taken to the intertemporal optimisation problem faced by each. It employs an exponential consumption equation that links a group's real per capita consumption expenditure to real per capita disposable income and the real interest rate. This equation is calibrated for each group and region based on a set of initial (1997) age-specific saving rates from per capita disposable income. ${ }^{22}$ Importantly, these show transitions to negative saving with retirement in the older industrial regions. This gives rise to declines in average saving rates as populations age. The empirical studies on age-specific saving behaviour are less clear, however, when it comes to developing regions. In the case of China, only modest declines in saving rates are recorded when people retire. This is due partly to the complication that a comparatively large proportion of consumption spending by the Chinese elderly is probably financed from the income of younger family members. We have attempted to take this into account in selecting the age-gender income weights and initial saving rates for China. ${ }^{23}$ If these rates represent Chinese behaviour accurately, they imply that ageing in China can be expected to have less impact on the average Chinese saving rate than it does in the older industrial economies.

\section{Constructing the baseline scenario}

The baseline scenario represents a business-as-usual projection of the global economy through to 2030. Although policy analysis can be sensitive to the content of this scenario, the focus of this chapter is on the extent of departures from it that would be caused by alternative trends in Chinese fertility on the one hand and aged participation rates on the other. Nonetheless, it is instructive to describe the baseline because all scenarios examined have in common a set of assumptions about future trends in productivity and because some exposition of the baseline makes the construction of departures from it clearer. 


\section{Exogenous factor productivity growth}

Exogenous sources of growth enter the model as factor productivity growth shocks, applied separately for each of the model's five factors of production (land, physical capital, natural resources, production labour and professional labour). Simulated growth rates are sensitive to productivity growth rates since the larger these are for a particular region, the larger is that region's marginal product of capital. The region therefore enjoys higher levels of investment and hence a double boost to its per capita real income growth rate. The importance of productivity notwithstanding, the empirical literature is inconsistent as to whether productivity growth has been faster in agriculture or in manufacturing and whether the gains in any sector have enhanced all primary factors or merely production labour. The factor productivity growth rates assumed in all scenarios are drawn from a new survey of the relevant empirical literature (Tyers et al. 2005). Agricultural productivity grows more rapidly than that in the other sectors in China, along with Australia, Indonesia, other East Asian countries, India and other South Asian countries. This allows continued shedding of labour to the other sectors. ${ }^{24}$ In the other industrialised regions, the process of labour relocation has slowed and labour productivity growth is slower in agriculture. In the other developing regions, the relocation of workers from agriculture has tended not to be so rapid.

Interest premiums. The standard GTAP-dynamic model takes no explicit account of financial market maturity or investment risk and so tends to allocate investment to regions that have high marginal products of physical capital. These tend to be labour-abundant developing countries whose labour forces are still expanding rapidly. Although the raw model finds these regions attractive prospects for this reason, we know that considerations of financial market segmentation, financial depth and risk limit the flow of foreign investment at present and that these are likely to remain important in the future. To account for this, we have constructed a 'pre-baseline' simulation in which we maintain the relative growth rates of investment across regions. In this simulation, global investment rises and falls but its allocation between regions is thus controlled.

To do this, the interest premium variable (GTAP-dynamic variable SDRORT) is made endogenous. This creates wedges between the international and regional borrowing rates. They show high-interest premiums for the populous developing regions of Indonesia, India, South America and sub-Saharan Africa. Premiums tend to fall over time in other regions, where labour forces are falling or growing more slowly. Most spectacular is a secular fall in the Chinese premium. This is because the pre-baseline simulation maintains investment growth in China despite 
an eventual decline in its labour force. This simulation is therefore overly optimistic with respect to China and so we reject the drastic declines in the investment premium that it implies. In constructing the final baseline scenario, we allow a fall in China's premium by 1.5 percentage points. Assuming all Chinese agents can borrow at the government's long-term bond rate, which exceeds the corresponding US rate by 40 per cent, this assumes that continuing financial reforms will wipe out about one-third of the initial Chinese premium, at the rates specified in the model..$^{25}$ The time paths of all interest premiums are set as exogenous and regional investment is freed up in all regions. Investment is then retained as endogenous in the model's closure in all subsequent simulations.

The baseline projection. Overall baseline economic performance is suggested by Table 11.5, which details the average GDP and real per capita income growth performance of each region from 1997 to 2030 . In part because of its comparatively young population and hence its continuing rapid labour force growth, India attracts substantial new investment and is projected to take over from China as the world's most rapidly expanding region. Rapid population growth, however, detracts from India's real per capita income performance. By this criterion, China is the strongest performing region through the three decades. Indonesia and other East Asian countries are also strong performers, while the older industrial economies continue to grow more slowly. The African region enjoys good GDP growth performance but its high population growth rates limit its performance in per capita terms.

\section{Higher fertility rates versus higher aged participation}

Higher fertility rates

Following Sharping (2003) and the State Council of China (2000), two higherfertility scenarios are constructed. These differ only in their fertility rates. Death rates and migration behaviour are assumed to remain as in the baseline projection. The first higher-fertility scenario offers a comparatively stable Chinese birth rate, with the fertility rate trending from 1.90 to 1.80 in the three decades to 2030 . It is similar to the State Council's one-child policy, and to Sharping's 'tight rule, fraud as usual' scenario. The second scenario trends towards two children per couple throughout China, with a fertility rate of 2.3 achieved by 2030. It is similar to the State Council's 'two-child policy' and to Sharping's 'delayed two-child policy'. The implications for China's total population under these scenarios are indicated in Table 11.6.

The correspondence between these simulations and the State Council's projections is close. A transition to a two-child policy would raise the 2030 population 
by 11 per cent relative to the stable fertility case. Our low-fertility baseline, on the other hand, achieves a 2030 population 7 per cent below the stable fertility case. These implications are displayed graphically in Figure 11.2. Critically, the associated labour force changes are smaller in magnitude and transitions occur earlier than those in the populations. The Chinese population ages in all three scenarios, but more slowly the higher the fertility rate. This can be seen from the non-working-aged dependency ratio in Figure 11.3. While it rises substantially by 2030 in all three cases, there are discernable differences, with the two-child policy yielding a 2030 ratio that is lower by four percentage points than the low-fertility baseline.

The three main avenues through which higher fertility affects economic performance are via the labour force, which it expands; the savings share of income, which tends to rise with the share of the population of working age; and the product composition of consumption, which more strongly reflects the preferences of the young when population growth accelerates. The comparisons made by Tyers et al. (2005) suggest a general ranking that has the labour force avenue most commonly the strongest with the savings rate avenue next and with the influence of age-specific consumption preferences comparatively small. This is indeed borne out. The labour force effect can first be seen through its impact on the non-working-age dependency ratio. This ratio expands under all scenarios in China, as shown in Figure 11.3, but it grows least in the two-child policy case. ${ }^{26}$

Turning to the other avenues, age-specific consumption preferences can be expected to have little influence in the results presented here since product markets are aggregated into three broad sectors and the capturing of generational differences in preferences requires fine product detail. As to the savings rate, for reasons discussed previously, the effects of Chinese fertility changes on average savings rates can be expected to be smaller than they are in the older industrialised regions. Beyond the dependency ratio, the dominant economic theme might be changes in China's labour force that alter the productivity of its capital and therefore the return on Chinese investment. Greater population growth thereby attracts an increased share of the world's savings into Chinese investment and so China's capital stock grows more rapidly. China's GDP, therefore, might be expected to be boosted substantially by increased fertility, through its direct and indirect influence over the supply of the two main factors of production: labour and capital. In per capita terms, however, the Solow-Swan predisposition towards slower real wage growth, combined with the need to reward foreign capital owners, suggests that the average Chinese will not derive economic benefit from increased fertility. 


\section{Table 11.5 Baseline real GDP and per capita income projections to 2030}

\begin{tabular}{|c|c|c|c|c|}
\hline & \multicolumn{2}{|c|}{$\begin{array}{l}\text { Per cent change in } \\
2030 \text { over } 1997\end{array}$} & \multicolumn{2}{|c|}{$\begin{array}{c}\text { Implied average annual growth rate } \\
\text { per cent per annum }\end{array}$} \\
\hline & Real GDP & $\begin{array}{c}\text { Real per } \\
\text { capita income }\end{array}$ & Real GDP & $\begin{array}{c}\text { Real per } \\
\text { capita income }\end{array}$ \\
\hline Australia & 262 & 178 & 4.0 & 3.1 \\
\hline North America & 253 & 171 & 3.9 & 3.1 \\
\hline Western Europe & 159 & 178 & 2.9 & 3.1 \\
\hline Central Europe and & & & & \\
\hline former Soviet Union & 205 & 210 & 3.4 & 3.5 \\
\hline Japan & 166 & 217 & 3.0 & 3.6 \\
\hline China & 340 & 378 & 4.6 & 5.0 \\
\hline Indonesia & 490 & 376 & 5.5 & 4.9 \\
\hline \multicolumn{5}{|l|}{ Other East } \\
\hline Asian countries & 529 & 373 & 5.7 & 4.8 \\
\hline India & 565 & 291 & 5.9 & 4.2 \\
\hline \multicolumn{5}{|l|}{ Other South } \\
\hline Asian countries & 430 & 127 & 5.2 & 2.5 \\
\hline South America & 293 & 149 & 4.2 & 2.8 \\
\hline \multicolumn{5}{|l|}{ Middle East and } \\
\hline North Africa & 280 & 104 & 4.1 & 2.2 \\
\hline Sub-Saharan Africa & 360 & 114 & 4.7 & 2.3 \\
\hline Rest of world & 336 & 159 & 4.6 & 2.9 \\
\hline
\end{tabular}

Source: The (low fertility) baseline projection described in the text.

\section{Table 11.6 The Chinese population under alternative demographic scenarios, 2000-2030a}

\begin{tabular}{lccccc}
\hline Millions & $\begin{array}{c}\text { Baseline: low (declining) } \\
\text { fertility1.90 to } 1.45\end{array}$ & \multicolumn{2}{c}{$\begin{array}{c}\text { Stable fertility (one-child } \\
\text { policy): } 1.90 \text { to } 1.80\end{array}$} & \multicolumn{2}{c}{$\begin{array}{c}\text { Transition to two-child } \\
\text { policy: } 1.90 \text { to } 2.30 \\
\text { State Council }\end{array}$} \\
& 1,252 & 1,270 & 1,253 & 1,270 & 1,257 \\
2000 & 1,311 & 1,344 & 1,328 & 1,369 & 1,369 \\
2010 & 1,321 & 1,393 & 1,369 & 1,466 & 1,462 \\
2020 & 1,296 & 1,396 & 1,382 & 1,518 & 1,536 \\
2030 & & & & & \\
\end{tabular}

Notes: ${ }^{a}$ The base year for our simulations is 1997 , when China's fertility rate was approximately $1.91 .{ }^{\mathrm{b}}$ The comparable simulation for stable fertility by the State Council of China holds the one-child policy constant as at present; the corresponding projection by Sharping is entitled 'tight rule, fraud as usual'.

Source: Sharping, T., 2003. Birth Control in China 1949-2000: population policy and demographic development, RoutledgeCurzon, London; State Council of China, 2000. China Development Studies: the selected research report of the Development Research Centre of the State Council, Development Research Centre of the State Council of China, China Development Press; and simulations using the model described in the text. 
Figure 11.2 Growth scenarios for China's population and labour force, 1995-2035a

Population

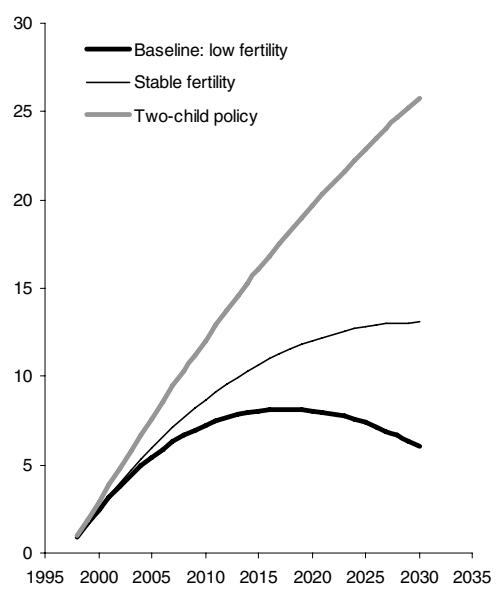

Labour force

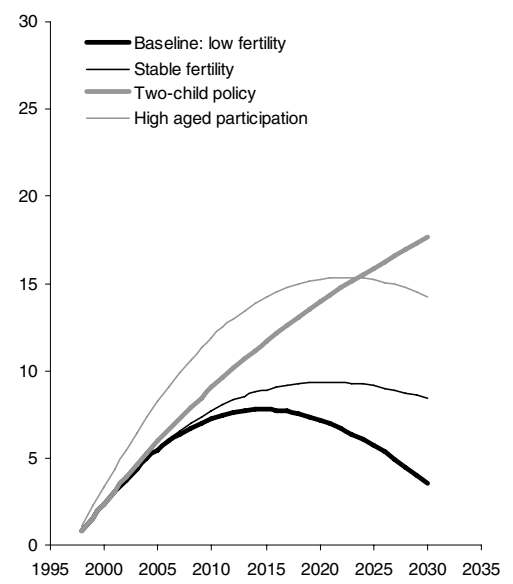

Notes: ${ }^{a}$ These are cumulative percentage departures from the base year, 1997.

Source: Model simulations.

Figure 11.3 Four scenarios for the Chinese non-working-aged (60+) dependency ratio, $1995-2035^{\text {a }}$ (per cent)

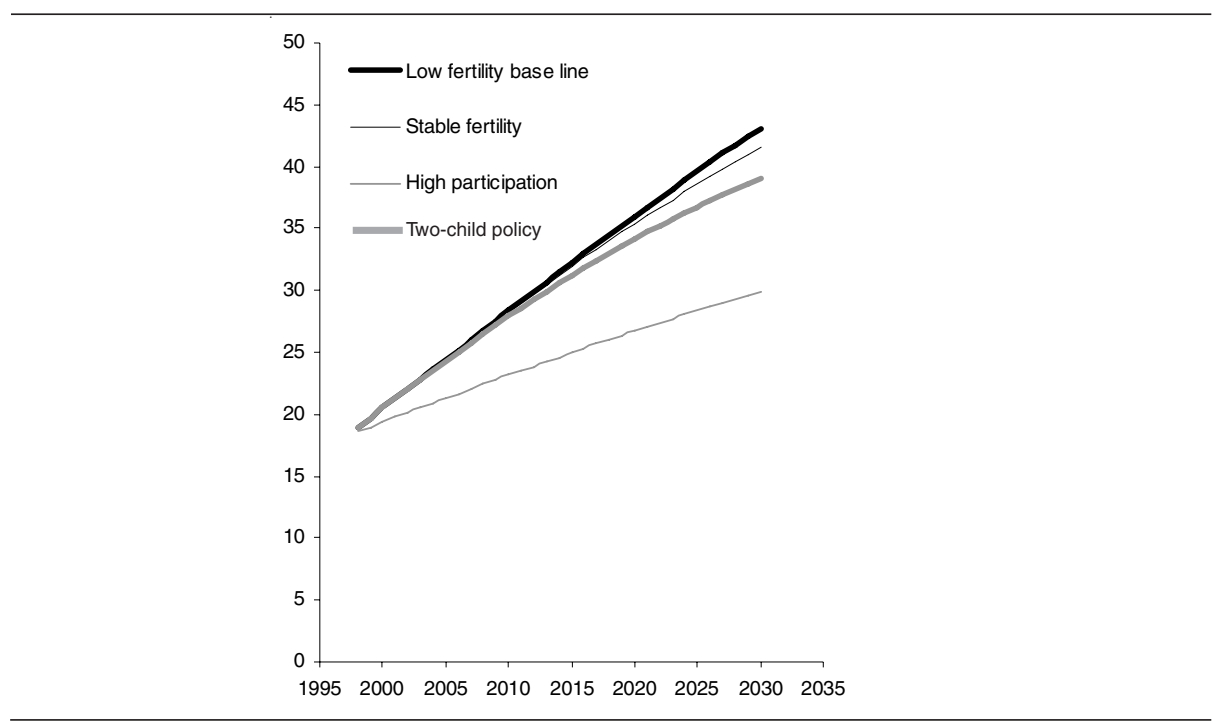

Source: Model simulations. 
These expectations are indeed borne out in our simulations (Table 11.7). Higher fertility, relative to the baseline, does raise the rate of return on installed capital in China and hence the level of investment. In turn, China's GDP is higher (Figure 11.4). Yet higher fertility slows real wage growth, due to the increased relative abundance of labour and, in combination with the repatriation of an increased proportion of the income accruing to capital, ${ }^{27}$ this causes real per capita income also to grow more slowly. A further negative complication is the large-country effect: as China's trade with the rest of the world expands, it turns its terms of trade against itself. This effect is small overall but of growing significance late in the period. ${ }^{28}$ The corresponding dynamics of the real production wage and real per capital income are illustrated in Figure 11.5.

\section{Higher aged labour-force participation}

Here we ask how different the economic changes would be were fertility to remain low, as in the baseline, and were China's aged labour-force participation rates to approach those currently observed in Japan. Male 60+ participation is set to rise from 24 per cent in 1997 to 43 per cent in 2030, while female 60+ participation rises from 4 per cent to 21 per cent. The economic implications of these changes are summarised in Table 11.8.

A key bottom line is the effect of each policy scenario on real income per capita. The two-child policy slows real per capita income growth for reasons already discussed (Figure 11.5). The high participation simulation achieves almost the same GDP growth without this loss in per capita welfare relative to the low-fertility baseline. This happens because higher aged participation expands the workforce much faster than fertility does so there is an earlier growth dividend. Yet the additional output is achieved at the expense of the leisure that would otherwise be enjoyed by the aged. As long as continuing to work is net life-enriching, however, there are net gains at least as large as the per capita real income gains shown.

As already noted, the saving rates of China's elderly are assumed to be not all that different from those of working-aged people, due largely to estimation difficulties associated with intergenerational transfers. For example, initial saving rates (in 1997) among 40-59 year olds were set at 40 per cent of personal disposable income, compared with 31 per cent for $60+$ year olds. These figures are similar to India's and close to other East Asian countries, but significantly different from Europe's and North America's, where retirees have negative savings rates (as large as -30 per cent in North America). If the savings rate of China's elderly in the future turns out to be much lower than assumed, the economic gains from higher labour-force participation will be even larger than we project here. 


\section{Table 11.7 Economic effects of faster Chinese population growth to 2030} (per cent departures of the two-child policy from the low-fertility baseline)

\begin{tabular}{lcccccc}
\hline \multicolumn{1}{c}{$\begin{array}{c}\text { Real } \\
\text { investment }\end{array}$} & Real GDP & $\begin{array}{c}\text { Real GNP } \\
\text { per capita }\end{array}$ & $\begin{array}{c}\text { Real } \\
\text { production } \\
\text { wage }\end{array}$ & $\begin{array}{c}\text { Rate of } \\
\text { return on } \\
\text { installed capital }\end{array}$ & $\begin{array}{c}\text { Terms of } \\
\text { trade }\end{array}$ \\
2010 Stable fertility & 0.7 & 0.3 & -1.1 & -0.2 & 0.1 & - \\
Two-child policy & 2.7 & 1.1 & -3.6 & -0.6 & 0.4 & - \\
2020 Stable fertility & 2.9 & 1.5 & -2.7 & -0.6 & 0.2 & -0.1 \\
Two-child policy & 8.8 & 4.7 & -7.3 & -1.9 & 0.6 & -0.5 \\
2030 Stable fertility & 5.3 & 3.6 & -4.4 & -1.4 & 0.3 & -0.6 \\
Two-child policy & 14.7 & 10.3 & -11.0 & -3.8 & 0.6 & -1.6 \\
& & & & & &
\end{tabular}

Source: The baseline, stable-fertility and two-child polity projections from the model described in the text.

Figure 11.4 Chinese real GDP, departures from the baseline, 1995-2035a (per cent)

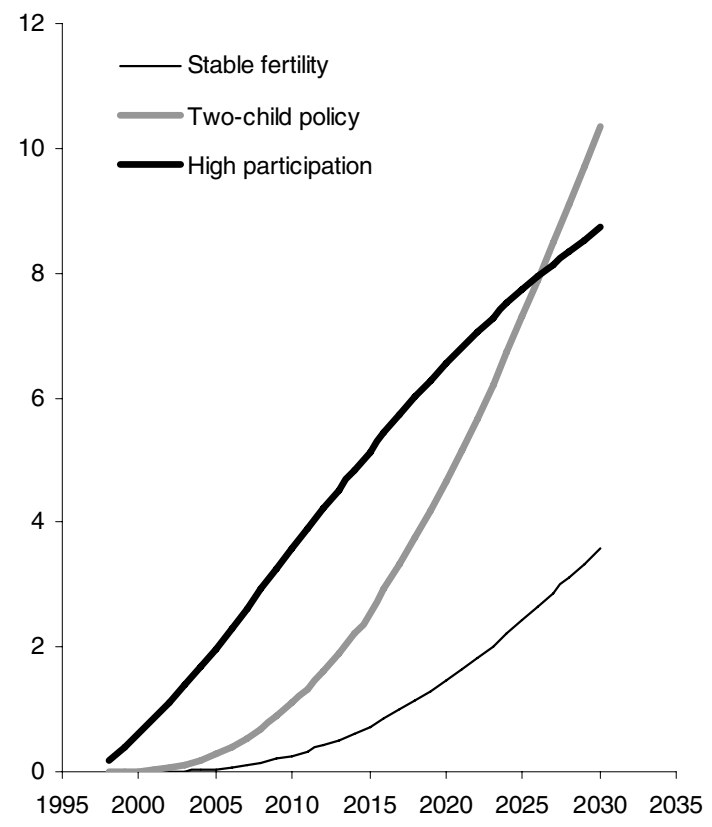

Source: Model simulations. 


\section{Figure 11.5 Chinese real wage and per capita income, departures from the baseline, 1995-2035ª (per cent)}

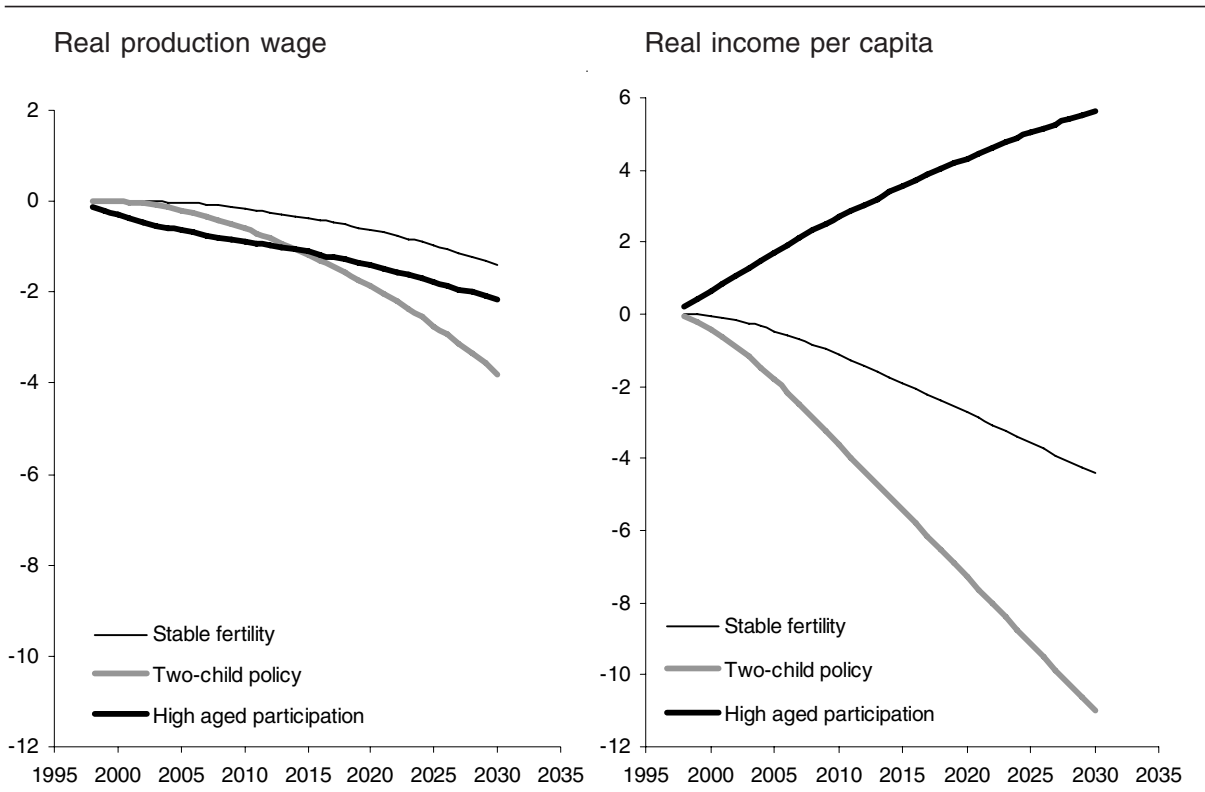

Note: ${ }^{a}$ These are percentage departures from the baseline simulation for each year. Note that the baseline assumes declining fertility in China.

Source: Model simulations.

\section{Table 11.8 Economic effects of increased aged labour-force participation, 2010-2030 (percentage departures of the high-participation simulation from the baseline)}

\begin{tabular}{lcccccc}
\hline & $\begin{array}{c}\text { Real } \\
\text { investment }\end{array}$ & Real GDP & $\begin{array}{c}\text { Real GNP } \\
\text { per capita }\end{array}$ & $\begin{array}{c}\text { Real } \\
\text { production } \\
\text { wage }\end{array}$ & $\begin{array}{c}\text { Rate of } \\
\text { return on } \\
\text { installed capital }\end{array}$ & $\begin{array}{c}\text { Terms of } \\
\text { trade }\end{array}$ \\
2010 & 7.5 & 3.6 & 2.7 & -0.9 & 0.4 & -0.3 \\
2020 & 9.3 & 6.5 & 4.3 & -1.4 & 0.02 & -0.9 \\
2030 & 9.7 & 8.7 & 5.6 & -2.2 & -0.8 & -1.4 \\
\hline
\end{tabular}

Note: ${ }^{a}$ Here the low-fertility baseline is compared with a corresponding low-fertility simulation in which risk premium reductions are calculated to achieve the same GDP growth as would be achieved if the two-child policy was invoked.

Source: The baseline and high-participation projections from the model described in the text. 
One caveat that is worth noting is that the labour-force participation rate for younger females, like all participation rates, is assumed to trend exogenously. In fact, we might expect it to be related to fertility because of child-care demands. For example, a relaxation of the one-child policy could result in higher fertility and hence lower participation rates, particularly in the absence of child-care centres and parent-friendly labour policies. Complicating this further is the possibility of young mothers going out to work while grandparents undertake child care. Higher participation rates among the aged population could result in reduced fertility or lower participation rates among younger women. This suggests that labour-force participation rates are likely to be endogenous and, in the scenarios depicted here, the benefits of higher aged participation rates could in fact be offset to some extent by lower participation rates in other age categories.

\section{Conclusions}

China's economic growth has hitherto depended on its relative abundance of production labour and its increasingly secure investment environment. Within the next decade, however, China's labour force is likely to begin contracting. This will set its economy apart from other developing Asian countries where relative labour abundance will increase, as will relative capital returns. This expectation is confirmed in this chapter using a new global demographic model that is integrated with an adaptation of the GTAP-dynamic global economic model in which regional households are disaggregated by age and gender. A transition to a two-child policy in China is shown to boost its GDP growth, enlarging the projected 2030 Chinese economy by about one-tenth. Yet this would slow the growth rate of real per capita income, reducing the level projected for 2030 by one-tenth.

Almost the same GDP growth performance might be achieved with continued low fertility, if China's aged participation rates rise gradually through 2030 to approximate the rates currently observed in Japan. Considering that China's current aged participation rates are very low by Asian standards, there is considerable scope for this expansion as the level of life expectancy at 60 and the proportion of workers in the private sector continue to grow. To the extent that increased employment of the aged might be considered sufficiently life-enriching to offset the decline in leisure time, the results suggest that this scenario offers superior per capita real income growth to what might be achieved via a policy-driven boost to fertility.

Not only do higher fertility rates offer less in terms of per capita income growth, there is much uncertainty regarding the efficacy of pro-fertility policies in lowfertility countries, with evidence from industrial countries now grappling with the 
same issue sketchy at best. With 'heavy-handed methods of persuasion' no longer a viable option, the Chinese government would need to consider market-based incentives, such as tax breaks and family allowances, and policies to ease the burden for working mothers. The low likelihood of identifying and implementing effective pro-fertility policies, combined with the long lag until those policies would alter the working-age proportion of the population, suggests that alternative policy approaches might be preferred.

The approach emphasised in this chapter focuses on aged labour-force participation rates, which were seen to be low and declining in China at the turn of this century. As longevity continues to rise, it seems reasonable to advocate later retirement as a way of expanding the proportion of workers and thereby reducing the burden placed on the fiscal system of a rapidly ageing population. Much more complicated is the impact that continuing reforms of the pension system will have on retirement decisions and therefore on aged participation rates, since different measures to deal with pension-related budgetary pressures will have profoundly different effects. As Greenspan (2004:782) points out, higher payroll taxes to finance ageing-related problems will exacerbate the slow-down in the growth of labour supply by diminishing the returns to work, while 'policies promoting longer working life could ameliorate some of the potential demographic stresses'. The interaction between pensions, savings and aged participation is clearly an area worthy of further research.

As China grapples with ways to cope with the burden of ageing-a problem primarily in the domain of the industrial world-it also faces challenges associated with its continuing transition and economic development. Successful industrial restructuring might well lead to higher labour-force participation rates, as people choose to work longer to take advantage of new opportunities offered by the rising non-state sector. On the other hand, it is possible that industrial restructuring might lead to even wider spread redundancies and rising unemployment. This risk will be reduced if labour markets can be made increasingly flexible, through the removal of institutional and other barriers to rural-urban and intersectoral migration. While not all that helpful for the current generation of retirees, whose average educational attainment is extremely low, ${ }^{29}$ investment in education is likely to contribute to higher participation rates in the future, with evidence already showing an increasingly strong and positive correlation between education levels and participation (Zhang et al. 2002). Education and labour-market policies will be beneficial not only through their impact on labour-market participation, but will contribute to improvements in factor productivity, which will yield further income gains on those projected here. 


\section{Acknowledgments}

Funding for the research described in this chapter is from Australian Research Council Discovery Grant No. DP0557889. Thanks are due to Heather Booth, Siew Ean Khoo and Ming Ming Chan for helpful discussions about the demography, Robert McDougall and Hom Pant for their constructive comments on the economic analysis and to Terrie Walmsley for technical assistance with the GTAP database as well as useful discussions on baseline simulations. lain Bain provided research assistance.

\section{Notes}

1 See Bloom and Williamson 1997 for a discussion of the demographic dividend across developing countries; and Cai and Wang 2005 for a detailed examination of its implications for China. A recent news article, entitled 'Family planning becomes a controversial topic' (Xinhuanet, available online at <http://www.cpirc.org.cn/en/enews20051230htm> accessed 30 December 2005), reports that academics and government officials are showing increasing interest in the relaxation of the one-child policy.

2 The eleventh Five-Year Plan (2006-10) was delivered by Premier Wen Jiabao in March 2006 at the Fourth Session of the Tenth National People's Congress. In it, China's GDP is projected to grow by 7.5 per cent between 2005 and 2010, with per capita GDP increasing from 13,985 yuan to 19,270 yuan in the same period. These projections are in line with the central government's ambitions to raise the level of GDP in 2020 to four times the level in 2000, requiring an annual GDP growth rate of 7.2 per cent (Cai and Wang 2005).

3 See United Nations 2005; Peng 2005; Cai and Wang 2005; Heller and Symansky 1997; and Hussain 2002.

4 These figures are similar to the proportion of the United States' population over 65, which will rise from 12 per cent to perhaps 20 per cent in 2035 (Greenspan 2004).

5 See Tyers and Golley 2006 for an alternative response, which focuses on financial-sector reforms.

6 See the excellent discussion of population policy in low-fertility countries in Demeny 2003 for further details.

7 For example, a pilot program established in Liaoning in 2000 has recently been expanded to Jilin and Heilongjiang in 2004 (State Council 2005). See World Bank 1997a and Wang et al. 2004 for further details on the pension system.

8 See also Shi and Tyers 2004 and Tyers et al. 2005.

9 The GTAP-dynamic model is a development of its comparative static progenitor, GTAP (Hertel 1997). Its dynamics are described in lanchovichina and McDougall 2000.

10 The demographic sub-model has been used in stand-alone mode for the analysis of trends in dependency ratios. For a more complete documentation of the sub-model, see Chan and Tyers 2006.

11 The subdivision between production and professional labour accords with the International Labour Organisation's occupation-based classification and is consistent with the labour division adopted in the GTAP database. See Liu et al. 1998.

12 Mothers in families providing production labour are assumed to produce children who will grow up to also provide production labour, while the children of mothers in professional families are correspondingly assumed to become professional workers. 
13 Immigration and emigration are also age and gender specific. The model represents a full matrix of global migration flows for each age and gender group. Each of these flows is currently set at a constant proportion of the population of its destination group. See Tyers 2005 and Tyers et al. 2006 for further details.

14 The migration rates and the corresponding birth rates are listed in detail in Tyers et al. 2005 (Tables 2-5).

15 In this discussion, the skill index, $s$, is omitted because birth and death rates, and life expectancies at 60 , do not vary by skill category in the version of the model used.

16 Note that, as regions become more advanced and populations in the production-worker families become comparatively small, the skill transformation rate has a diminishing effect on the professional population. These transformation rates are made endogenous to real per capita incomes and to the skilled wage premium in Tyers et al. 2006.

17 See Tyers et al. 2005 (Tables 11 and 12) for further details.

18 The resulting participation rates are listed by Chan and Tyers 2006 (Table 10).

19 All these dependency ratios are defined in detail by Chan and Tyers 2004.

20 These projections are low compared with those by the State Council of China (2000) and Sharping (2003), yet those make no attempt to allow Chinese fertility to follow the declining trends observed in neighbouring countries.

21 The analytics of income splitting are described in detail by Tyers et al. 2005 .

22 For further details, see Tyers et al. 2005.

23 New research by Kinugasa and Mason (2005) and Feng and Mason (2005) offers useful results on the relationship between age and saving in China. For further details on the saving rates used in our model, see Tyers and Golley 2006.

24 Wang and Ding (2006) recently estimated that there were 40 million surplus workers in China's agricultural sector. While underemployment is not explicit in our model, the assumption of high labour productivity growth in agriculture implies that agriculture is capable of shedding labour more quickly than other sectors. This essentially mimics the surplus labour problem, which is thereby accounted for implicitly.

25 See Tyers and Golley 2006 for further details.

26 This result could have a number of economic implications that are not captured in our model, including that higher fertility would necessitate lower rates of distorting taxes to finance aged pensions and public health systems. Our scenarios maintain constant tax rates and fiscal deficits.

27 The more correct way to see the capital income effect is to recognise that China is - and these simulations suggest it will continue to be-a net saving region. The attraction of increased investment merely relocates the source of capital income but does little to raise its net value.

28 Empirical evidence for such terms-of-trade effects from growth is variable. In many cases, developing-country expansions have not caused adverse shifts in their terms of trade because their trade has embraced new products and quality ladders in ways not captured by our model. See the literature on the developing-country exports fallacy of composition argument, which includes Lewis 1952; Grilli and Yang 1988; Martin 1993; Singer 1998; and Mayer 2003.

29 In 2000, 29 per cent of China's 35-39 year olds had low educational attainment (primary school or less) compared with 83 per cent of 60-64 year olds and 91 per cent of 65-69 year olds. 


\section{Appendix Figure A11.1 The demographic sub-model}

Female population
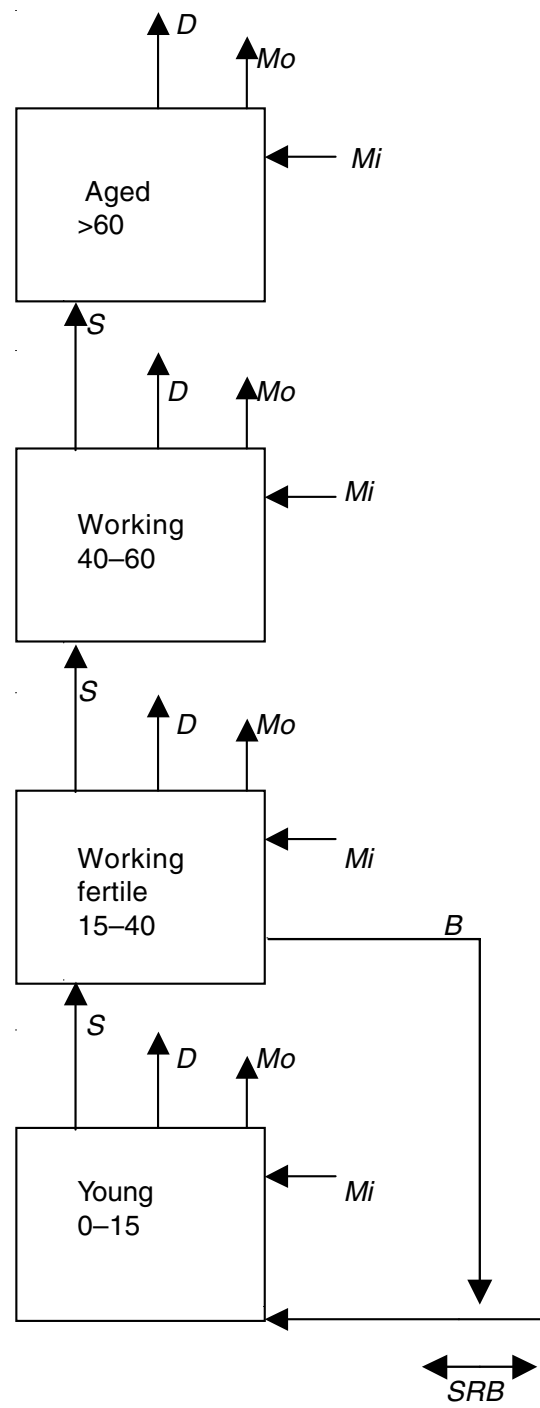

Male population

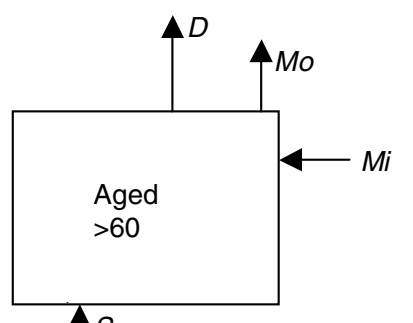

Working 40-60
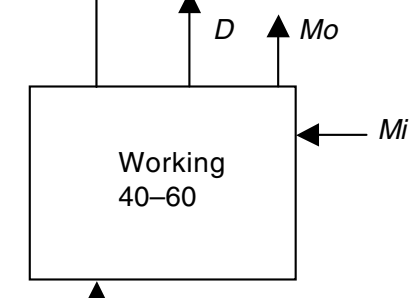

$S$

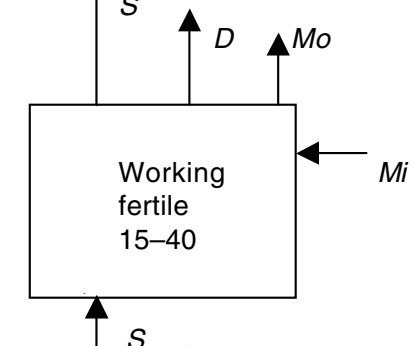

Mi

Notes: $D$ Deaths, $S$ Survival, $B$ Births, $M i$ Immigration, Mo Emigration, SRB Sex ratio at birth. 